Journal of Advanced Research in Fluid Mechanics and Thermal Sciences

\title{
Investigation of Chip Formation and its Grain Structure using Vegetable Oil Based Lubricants
}

\author{
Roman Kalvin ${ }^{1,3}$, Juntakan Taweekun ${ }^{2,}{ }^{,}$, Muhammad Waqas Mustafa ${ }^{3}$, Saba Arif ${ }^{1}$, Abdullah Javed $^{3}$ \\ Energy Technology Program, Faculty of Engineering, Prince of Songkla University Hat Yai, Thailand \\ Department of Mechanical Engineering, Faculty of Engineering, Prince of Songkla University Hat Yai, 90112 Songkhla, Thailand \\ Department of Mechanical Engineering, Wah Engineering College, Wah Cantt. Pakistan
}

\section{ARTICLE INFO}

\section{Article history:}

Received 29 March 2021

Received in revised form 1 June 2021

Accepted 9 June 2021

Available online 17 July 2021

\section{Keywords:}

Vegetable oils; drilling; chip structure; mild steel

\section{ABSTRACT}

This research aims to compare the chips formed by using different vegetable oil based lubricants such as coconut oil, cooking oil, hair oil etc. For this purpose, drilling was affordable and easy process which was used. The process was applied on AISI 1080 Mild Steel and chips and their grain structure were examined through Material Testing Microscope model TESCAN (MIRA 3 XMU Type) to check surface morphology. As a result of chip analysis through Material Testing Microscope; coconut oil gave better chip length with better grain structure. The lubricants or material can be changed to see the difference or resemblance of chip structure formed as a result.

\section{Introduction}

The lubrication technique in the machining processes was an important factor considered by analysts. The ease and efficiency of cutting process were under observation during machining processes. Drilling was one of the most important machining processes which was and is used for producing holes and cavities in the work materials. In drilling, various types of lubricants were used to avoid friction between the contacting materials which were generally mineral oils based. The material removed from the work during a machining process was in the form of chips which can be recycled and reused if the grain structure is better and continuous.

Braga et al., worked on drilling of alloys of silicon-aluminum by using a diamond coated drill and minimum quantity lubrication technique [1]. There was not any advantage of using drill with diamond coat as compared to uncoated K10 drill.

Belluco and Chiffre [2] evaluated six cutting oils efficiency, using conventional HSS-Co tools, to drill AISI 316L stainless steel by measuring tool life, cutting forces, tool wear and chip formation. All vegetable oils had better results than the reference mineral oil. Nam et al., experimentally characterized the micro-drilling process by using MQL [3]. It was observed that the magnitudes of

\footnotetext{
* Corresponding author.

E-mail address: jantakan.t@psu.ac.th
}

https://doi.org/10.37934/arfmts.84.2.9297 
thrust forces and drilling torques were significantly reduced by using the nano-fluid minimum quantity lubrication using nano-diamond particles.

Ozcelik et al., worked on four cutting fluids performance, two distinct vegetable oils extracted from sunflower oil and two commercial type cutting fluids (mineral and semi-synthetic), on roughness of surface while drilling stainless steel AISI304 with HSSE tool [4]. Vegetable oils performed better as compared to mineral-based or semi-synthetic cutting oils. Fairuz et al., investigated the application of vegetable oils as a lubricant in drilling process to perceive the chip formation, tool wear and to predict weather coconut oil could give superior chip if used as lubricant in drilling process [5]. Rubio et al., worked on friction force between work material and tool used for making hole and concluded that sandwich type material was more appropriate for friction drilling process [6]. By proper cutting speed, reduced point angle and low feed rate; delamination can be decreased.

Davim et al., worked on the high speed drill having 118, 82 and 100 drill point angles and observed that temperature of drilling specimen increases with the increase in feed rate and the speed [7]. Davim and Reis worked on the penetrating effect parameters and condition of machining on surface roughness with time [8]. Harshness of surface was diminished from 7032 to $2032 \mu \mathrm{m}$ with cutting rate increment and feed lessening. Machining time was expanded from 7.4 to 31.5 seconds. Domingo et al., worked on required strength in drilling dry of PEEK GF30 a material of thermo plastic and forth. Composite penetrate was the more played influent factor [9].

Singh et al., worked on HSS exhibition, K20 carbide and HSS covered tin apparatuses in dry drilling of AISI 304 [10]. HSS covered tin penetrate demonstrate the most astounding execution with longer device life. Stein and David worked on burr formation in drilling process and proposed that the inclusion of burr formation data in planning process [11]. It was concluded that by increasing feed sensitivity, speed and drill; wear can cause the increase in size and shape of burrs. Feng Ke et al., worked on chip removing motion and forces in two models to predict spiral and string chips formation. After analysis it was found that smoothness in chip formation and average chip length could be predicted qualitatively [12].

Lawal et al., worked on lubrication techniques by analyzing factors like work material, tool material and machining conditions [13]. After analysis, vegetable oils as lubricants were observed and preferred because of its extinguishing characteristics. Kim et al., analyzed chip formation using milling 360 brass with flute end mill [14]. It was observed that appreciable cutting could be if feed per tooth done is not so small. Davim et al., worked on the use of fluid during machining processes and predicted that flood coolant lubrication could replace MQL technique if parameters were chosen carefully [15].

Basavrajappa et al., worked on drills of carbide and work pieces of A122191155i cp and A12219/155 Si cp [16]. Senthil Kumar et al., worked on the machining parameters like cutting speed and feed rate [17]. Khalil et al., studied the machining characteristics (surface roughness, temperature and dimensional accuracy) of two dissimilar composite blends named LLDPE/PALMAC 95 -16 Palm Oil-Based Wax and LLDPE/PALMAC 98-18 Palm Oil-Based Wax [18].

After studied the literature it was observed that cutting speed and feed rate could be optimized using generic algorithm and obtained the results accordingly.

\section{Selection of Work Material and Lubricants}

A piece of AISI 1018 MILD STEEL with the dimensions of $92 \times 12 \times 12 \mathrm{~mm}$ (as shown in Figure 1), was used in the process because of its good physical and chemical properties. It contains 0.14 $0.20 \%$ of carbon and $98.81-99.26 \%$ iron and traces of some other elements like manganese, 
phosphorus and sulphur. An uncoated drill bit of High Speed Steel (HSS) was used which was $12 \mathrm{~mm}$ in diameter as shown in Figure 2. The Process was done on upright drilling machine. The lubricants used in this process were vegetable oils which were used in routine life and preferred because of ease of availability. The four type of oils were used which includes hair oil, cooking oil, olive oil and coconut oil.

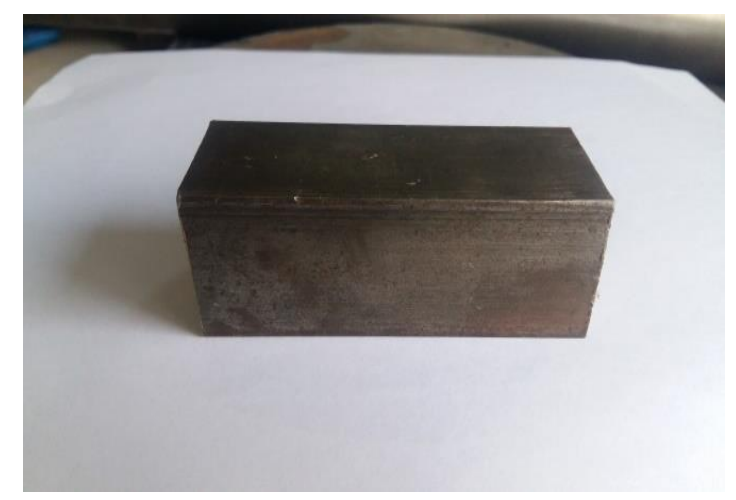

Fig. 1. AISI 1018 mild steel

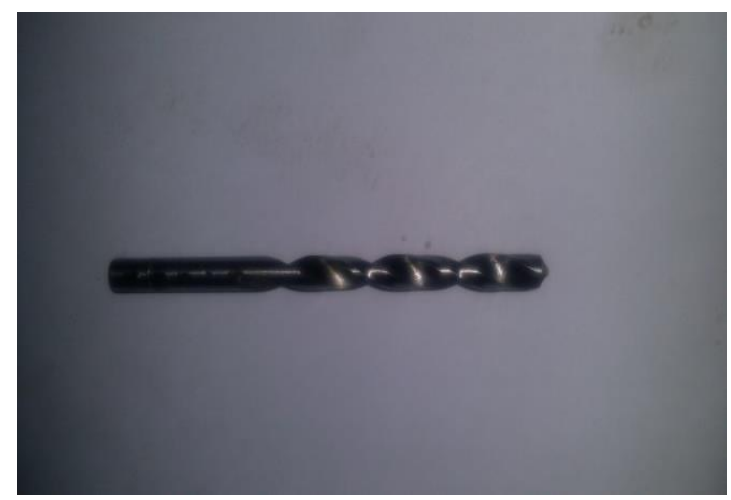

Fig. 2. HSS drill bit

\section{Experimental Procedure}

Drilling operation was performed on the MS material, using upright drill machine. The drilling was done at a constant speed to avoid the human errors in the process. The lubricants were applied constantly during the process to avoid the chances of low lubrication at any moment. Total four holes were drilled at an average depth of $23 \mathrm{~mm}$ each as shown in Figure 3. In each drill, different lubricant was used. The chips formed in each drill was collected from their respective holes and samples were gathered carefully. Each sample was named and differentiated as that of the lubricant oil being used. The chips obtained from the process were shown in Figure 4 - Figure 7.

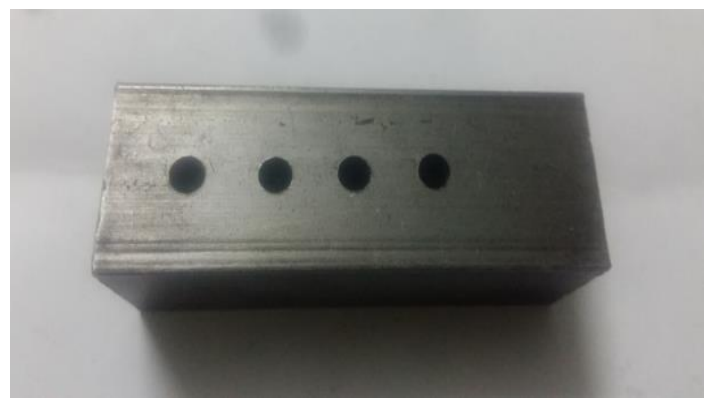

Fig. 3. MS material after Drilling 


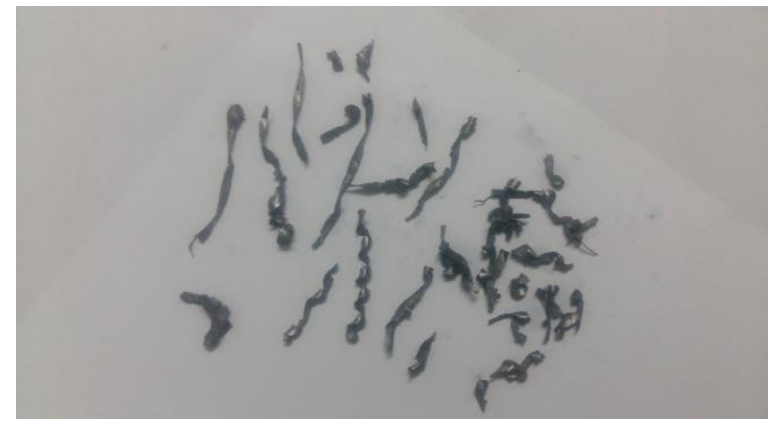

Fig. 4. Chips using coconut oil

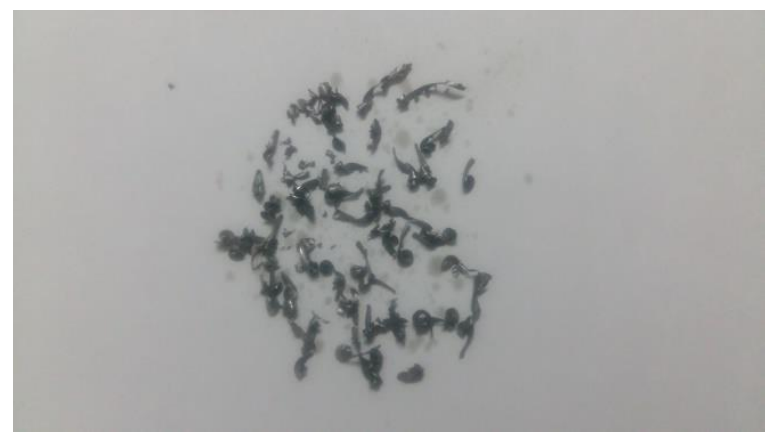

Fig. 6. Chips using olive oil

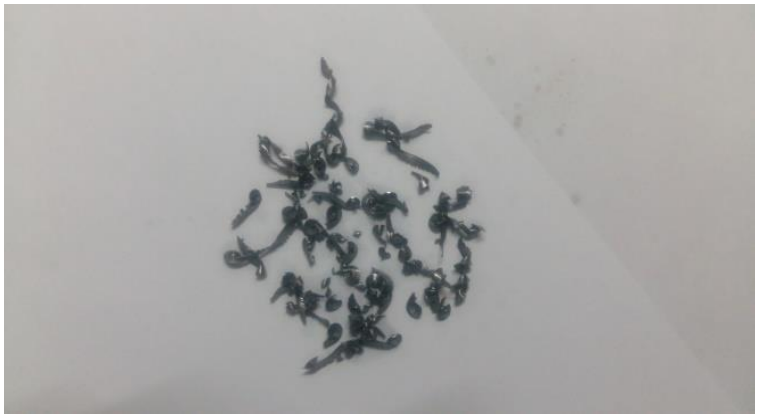

Fig. 5. Chips using cooking oil

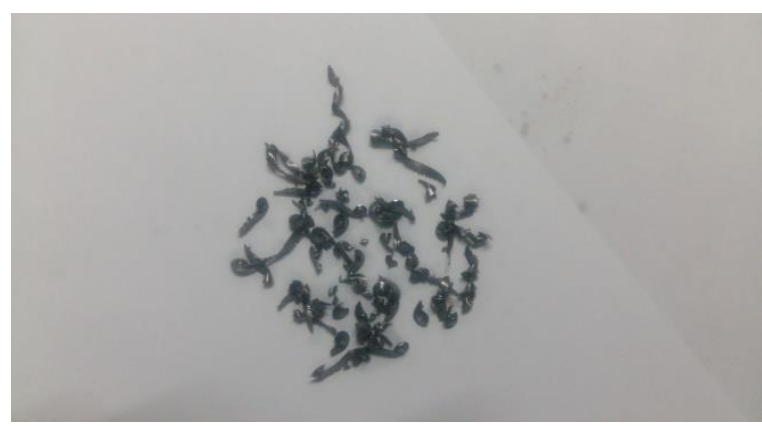

Fig. 7. Chips using hair oil

\section{Observations}

The purpose of this operation using different lubricants was to observe the grain structure and continuity of chips formed during the process. Chips and their grain structure were than examined through Material Testing Microscope model TESCAN (MIRA 3 XMU Type) to check surface morphology as shown in Figure 8 - Figure 11.

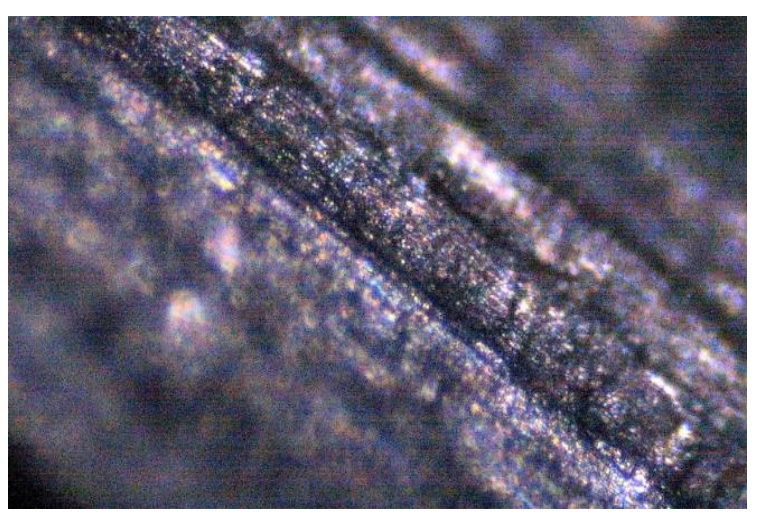

Fig. 8. Chip structure using coconut oil

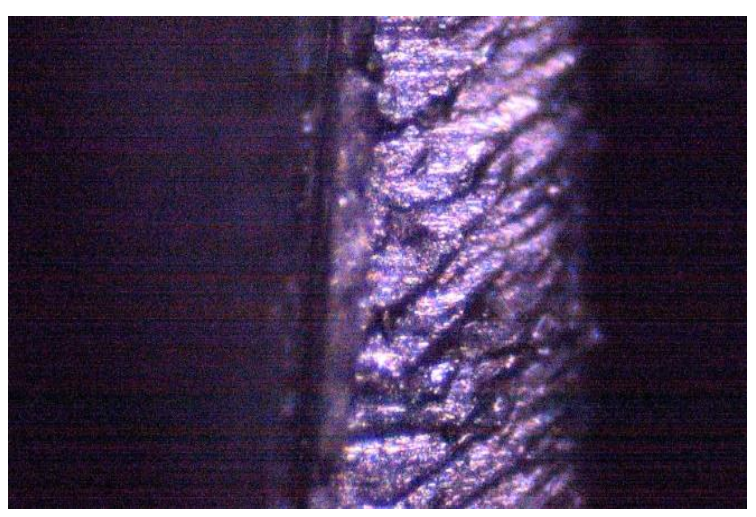

Fig. 9. Chip structure using cooking oil 


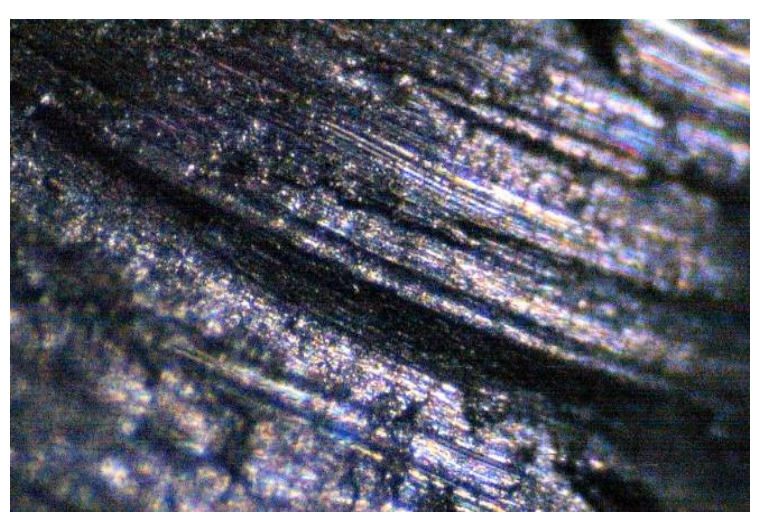

Fig. 10. Chip structure using olive oil

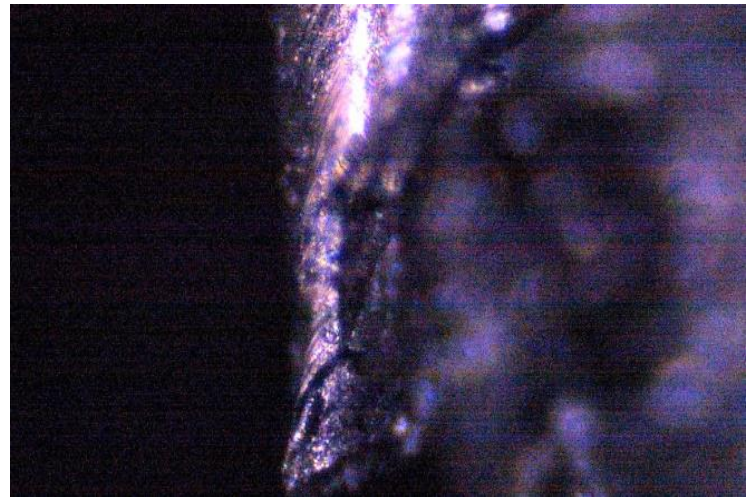

Fig. 11. Chip structure using hair oil

It was observed that the chip formed using coconut oil has a better grain structure, smooth surface and chip length than any lubrication oils and can be recycled and reused.

\section{Conclusion}

The use of lubricants in a machining process was necessary as it has a key role in the chip structure formation. As chips could be recycled and reused; so, the chip with continuous length and better grain structure could be used again in different processes. From this experiment, we concluded that the coconut oil could be used vastly to produce better chip structure, cost effective and non-reactive as well

In future, other organic oil based lubricants such as kerosene oil, jatropha, rapeseed oil etc. could also be used to see whether the chips structure formed as a result would be preferred or not. Also by varying RPM of machine and by varying applied vertical force in drill operation; experimentation would be done to analyze chip structure formed as a result. Other than that same technique could be applied on other materials such as copper bar, carbon steel bar, Silver bar etc. to observe whether these lubricants could give same chip structures or the chip structure varies.

\section{References}

[1] Braga, Durval U., Anselmo E. Diniz, Gilberto WA Miranda, and Nivaldo L. Coppini. "Using a minimum quantity of lubricant (MQL) and a diamond coated tool in the drilling of aluminum-silicon alloys." Journal of Materials Processing Technology 122, no. 1 (2002): 127-138. https://doi.org/10.1016/S0924-0136(01)01249-3

[2] Belluco, Walter, and Leonardo De Chiffre. "Performance evaluation of vegetable-based oils in drilling austenitic stainless steel." Journal of materials processing technology 148, no. 2 (2004): 171-176. https://doi.org/10.1016/S0924-0136(03)00679-4

[3] Nam, Jung Soo, Pil-Ho Lee, and Sang Won Lee. "Experimental characterization of micro-drilling process using nanofluid minimum quantity lubrication." International Journal of Machine Tools and Manufacture 51, no. 7-8 (2011): 649-652. https://doi.org/10.1016/j.ijmachtools.2011.04.005

[4] Ozcelik, Babur, Emel Kuram, Erhan Demirbas, and Emrah Şik. "Optimization of surface roughness in drilling using vegetable-based cutting oils developed from sunflower oil." Industrial Lubrication and Tribology(2011). https://doi.org/10.1108/00368791111140486

[5] Fairuz, M. A., M. J. Nurul Adlina, Azwan Iskandar Azmi, M. R. M. Hafiezal, and K. W. Leong. "Investigation of chip formation and tool wear in drilling process using various types of vegetable-oil based lubricants." In Applied Mechanics and Materials, vol. 799, pp. 247-250. Trans Tech Publications Ltd, 2015. https://doi.org/10.4028/www.scientific.net/AMM.799-800.247

[6] Rubio, J. Campos, A. M. Abrao, P. E. Faria, A. Esteves Correia, and J. Paulo Davim. "Effects of high speed in the drilling of glass fibre reinforced plastic: evaluation of the delamination factor." International Journal of Machine Tools and Manufacture 48, no. 6 (2008): 715-720. https://doi.org/10.1016/j.ijmachtools.2007.10.015

[7] J.P. Davim, F. Mata, V.N. Gaitonde, S.R. Karnik. "Drilling temperature of the specimen with increase in both cutting speed and feed rate." J Biomech Engineering 122, no. 2 (2010): 159-165. 
[8] Strenkowski, J. S., C. C. Hsieh, and A. J. Shih. "An analytical finite element technique for predicting thrust force and torque in drilling." International Journal of Machine Tools and Manufacture 44, no. 12-13 (2004): 1413-1421. https://doi.org/10.1016/j.ijmachtools.2004.01.005

[9] R. Domingo, M. García, M.A.Sebastián. "Vitality during the dry drilling of PEEK GF30, a thermoplastic material and polyether." J. Eng. Ind 96, no. 4 (2015): 1207-1215.

[10] A.P. Singh, M. Sharma, I. Singh. "Exhibitions of HSS, K2O strong carbide, and TiN-covered HSS apparatuses in dry drilling of AISI 304." (2016).

[11] Stein, Julie M., and David A. Dornfeld. "Burr formation in drilling miniature holes." Cirp Annals 46, no. 1 (1997): 63-66. https://doi.org/10.1016/S0007-8506(07)60776-8

[12] Ke, Feng, Jun Ni, and D. A. Stephenson. "Continuous chip formation in drilling." International Journal of Machine Tools and Manufacture 45, no. 15 (2005): 1652-1658. https://doi.org/10.1016/i.ijmachtools.2005.03.011

[13] Lawal, Sunday Albert, Imtiaz Ahmed Choudhury, and Yusoff Nukman. "A critical assessment of lubrication techniques in machining processes: a case for minimum quantity lubrication using vegetable oil-based lubricant." Journal of Cleaner Production 41 (2013): 210-221. https://doi.org/10.1016/i.jclepro.2012.10.016

[14] Kim, Chang-Ju, Matthew Bono, and Jun Ni. "Experimental analysis of chip formation in micro-milling." TECHNICAL PAPERS-SOCIETY OF MANUFACTURING ENGINEERS-ALL SERIES- (2002).

[15] Basavarajappa, S., G. Chandramohan, M. Prabu, K. Mukund, and M. Ashwin. "Drilling of hybrid metal matrix composites-Workpiece surface integrity." International Journal of Machine Tools and Manufacture 47, no. 1 (2007): 92-96. https://doi.org/10.1016/j.ijmachtools.2006.02.008

[16] Davim, J. P., P. S. Sreejith, R. Gomes, and C. Peixoto. "Experimental studies on drilling of aluminium (AA1050) under dry, minimum quantity of lubricant, and flood-lubricated conditions." Proceedings of the Institution of Mechanical Engineers, Part B: Journal of Engineering Manufacture 220, no. 10 (2006): $1605-1611$. https://doi.org/10.1243/09544054JEM557

[17] SenthilKumar, M., A. Prabukarthi, and V. Krishnaraj. "Study on tool wear and chip formation during drilling carbon fiber reinforced polymer (CFRP)/titanium alloy (Ti6Al4 V) stacks." Procedia engineering 64 (2013): $582-592$. https://doi.org/10.1016/i.proeng.2013.09.133

[18] Khalil, M., H. Radwan, F. Annuar, H. Azmi, and M. Z. Zakaria. "Study of Machining Characteristics of LLPDE/Palmac Palm Oil-Based Wax Blend for Prototype Application." Journal of Advanced Research Design 6, no. 1 (2015): 1120. 